\title{
Exploring House Price Dynamics: An Agent-Based Simulation with Behavioral Heterogeneity
}

\author{
Tolga A. Ozbakan ${ }^{1}$ (D) Serdar Kale ${ }^{2}$ (D) Irem Dikmen ${ }^{3}$ (D)
}

Accepted: 1 September 2018 / Published online: 15 September 2018

(c) Springer Science+Business Media, LLC, part of Springer Nature 2018

\begin{abstract}
The objective of this study is to contribute to the understanding of price formations in housing markets through an agent-based simulation that conceptualizes insights from behavioral economics. For this purpose, the study uses a prominent real estate market model as a benchmark and extends it to account for (1) behavioral heterogeneity and (2) dynamic agent interaction. The validation of the model is carried out by using real data from the Turkish housing market. The results show that the introduction of a fitness-based behavior-switching regime with myopic agents improves the extent to which the observed market behavior can be replicated, in comparison to the benchmark model.
\end{abstract}

Keywords Agent-based modeling · House prices · Behavioral economics · Evolutionary finance

\section{Introduction}

This study rests on a debate that has been developing over the last four decades about the nature of housing prices. On the two sides of this debate are neoclassical economists and behavioral economists who have different takes on the determinants of house prices as well as on the interpretation of price changes. The former perspective maintains that housing markets are efficient mechanisms in which participants make rational pricing decisions by utilizing all available information about market fundamentals. Accordingly, the perspective argues that prices reflect the fundamental value of the housing units, i.e., there is no long-term mispricing. On the other hand, the behavioral

\footnotetext{
Tolga A. Ozbakan

tolga@ozbakan.com

1 Technopark, Izmir Institute of Technology, Izmir, Turkey

2 Department of Architecture, Izmir Institute of Technology, Izmir, Turkey

3 Department of Civil Engineering, Middle East Technical University, Ankara, Turkey
} 
perspective raises questions about the efficiency of housing markets as well as the rationality of their participants and argues that house prices may deviate from their fundamental values.

In agreement with a growing body of literature, our study echoes the view that incorporating insights from behavioral economics can enhance the extant neoclassical housing market models. To support this statement, we use a well-known neoclassical real estate market model (Wheaton 1999) as a benchmark and extend it to experiment with behavioral heterogeneity among market participants. Specifically, we aim to answer the following two interrelated questions: To what extent does the inclusion of (1) behavioral heterogeneity and (2) dynamic market behavior enhance the benchmark model?

To meet this aim, we utilize an analytically tractable class of agent-based models known as Heterogenous Agent Models (HAMs). While HAMs were originally conceptualized for financial markets (See Hommes 2006 for a very in-depth review), recently they have been applied to real estate markets as well. For example, Burnside et al. (2011) proposed a model in which housing market participants have heterogeneous beliefs about fundamentals, i.e., some agents believe that these fundamentals will improve while others do not. Furthermore, although agents can update their prior beliefs in a Bayesian fashion, they have limited access to data. Another key feature of the model is an element that the authors refer to as social dynamics, i.e., agents meet randomly with each other and some of them change their prior beliefs about long-run fundamentals after these meetings. These features of the model generate a market in which home sales and prices display a sharp positive correlation. Dieci and Westerhoff (2012) published a HAM which attempted to account for the "forces of human psychology that drive international financial markets" in the context of housing markets. Notably, some agents in the model believe that housing prices will revert to a longrun fundamental steady state, while others maintain the view that the recent trends will continue. Furthermore, both groups of agents dynamically switch their beliefs based on market sentiment. Specifically, these behavioral changes in agent strategies occur according to how far housing prices deviate from a long-run fundamental steady state. Regarding the generated outcome, the authors report cyclical or even chaotic price dynamics under various market conditions. A study by Bijman (2012) included a model with similar characteristics. The model modifies Wheaton's (1999) study to include heterogeneous expectations and a natural vacancy rate. Like other HAMs, the agents in the model switch behaviors dynamically, but this time between rational and naive expectations. The generated price dynamics include quasi-periodic and chaotic behavior under specific parameter settings. Bolt et al. (2013) published a housing market model with heterogeneous expectations that links rental levels to prices via imputed rents. The results display nonlinear aggregate price fluctuations around the fundamental value with two non-fundamental equilibrium prices on either side of the fundamental price. Using quarterly data on rents and house prices, the authors estimate the model parameters for five different countries, namely the US, the UK, the Netherlands, Japan, and Switzerland. The study concludes that the data supports heterogeneity in expectations, with temporary switching between trend extrapolation and mean-reversion beliefs. Eichholtz et al. (2015) published an article with interacting heterogeneous agents with a focus on whether a fundamental factor or a trend explains 
house prices in the Netherlands. The authors find that agents in the housing market switch their expectations about future changes in house prices between fundamental and momentum strategies. Furthermore, the results of the study imply that neither fundamental variables nor recent trends explain housing price dynamics alone. Instead, both factors contribute to the variation in house prices and the relative importance of these factors vary over time. More recently, Campisi et al. (2018) introduced a housing market model following Dieci and Westerhoff (2012). Their model utilizes a time lag variable on the supply side. Furthermore, it extends the heterogeneity of the original model by considering naive expectations as well as a mix between naive and rational expectations. Like its predecessors, the study suggests that competition between distinct market strategies may lead to complex price dynamics.

In the remaining parts of this paper, we present a theoretical framework to explain the properties of the benchmark model (Wheaton 1999) and to propose our behavioral extensions. Next, we expound the computational representation of the extended model, followed by verification and experimentation. After validating the model in the empirical context of Istanbul's housing market, we conclude our paper.

\section{Theoretical Framework}

Like other prominent neoclassical real estate market models (e.g., Poterba 1984, 1991; DiPasquale and Wheaton 1992), the benchmark model used in this study (Wheaton 1999) establishes an analytical base that rests on market fundamentals. Specifically, it explains real estate prices with market fundamentals such as price elasticity of supply, price elasticity of rental demand, depreciation rate, construction cost, supply lag, and a constant discount rate. While maintaining the neoclassical individual rationality assumptions, it also includes backward-looking behavior where market participants extrapolate future prices based on current levels of rent. As such, it assumes neither efficiency of real estate markets, nor the presence of a rational expectations equilibrium. However, it does assume that a single representative agent reacts to market behavior, which brings about aggregate changes in prices and in quantities of the building stock. Accordingly, interactions between a heterogeneous set of individuals are nonexistent in the benchmark model.

The proposed model in this study extends the benchmark model by allowing heterogeneous behavior among market participants. It does so by replacing the representative agent by chartists who believe that the recent trends will continue and fundamentalists who believe that the market will follow an economic variable instead of trends (Harrison and Kreps 1978; Allen and Taylor 1990; Frankel and Froot 1987, 1990; Brock and Hommes 1997, 1998). Furthermore, the proposed model allows its agents to change their behavior dynamically based on a well-known epidemic model (Kirman 1993) and an evolutionary learning process (Eichholtz et al. 2015). This implies that, in agreement with prominent behavioral studies (e.g., Simon 1955; Tversky and Kahneman 1974; Kahneman and Tversky 1979, 1984), market participants in the proposed model are not fully rational. Specifically, while they may update their existing beliefs when new information becomes available, their decisions may still be incompatible with theories of expected utility (Barberis and Thaler 2003; Hommes 2006). 


\subsection{The Benchmark Model}

The benchmark model represents rental demand as a dynamic function $\left(D_{t}\right)$ that depends on an exogenous economic "demand instrument" $\left(E_{t}\right)$, a demand constant $(A)$, and the rent amount $\left(V_{t}\right)$ with a constant elasticity $(\varepsilon)$ as shown below:

$$
D_{t}=A E_{t} V_{t}^{-\varepsilon}
$$

In so doing, it assumes market-clearing conditions, i.e., rents adjust until demand equals the current stock of space $\left(S_{t}\right)$, which leads to the following short run relationship:

$$
V_{t}=\left(\frac{S_{t}}{A E_{t}}\right)^{\frac{1}{-\varepsilon}}
$$

On the supply side, the stock of real estate evolves according to the following difference equation, where $\delta$ represents the constant depreciation rate of stock as suppliers deliver a flow of new units $\left(C_{t}\right)$ with a lag of $n$ periods after construction begins:

$$
\frac{S_{t}}{S_{t-1}}=1-\delta+\left(\frac{C_{t-n}}{S_{t-1}}\right) .
$$

Therefore, the difference in stock between two time periods increases with the depreciation rate and decreases with the ratio of new construction to the existing stock. This ratio, in turn, is a function of the asset price itself. In other words, as prices go up, the ratio of new construction to the existing stock increases at a rate defined by the supply constant $(B)$ and the price elasticity of supply $(\eta)$ :

$$
\left(\frac{C_{t-n}}{S_{t-1}}\right)=B P_{t}^{\eta} .
$$

In the above formulation, the elasticity of supply determines the ratio of new construction to the existing stock levels. More importantly, by relating future prices of $n$ periods ahead to the current rents $V_{t}$ and a constant capitalization rate $(r)$ the benchmark model allows economic agents to use a backward-looking expectation scheme:

$$
P_{t}=\frac{V_{t-n}}{r}
$$

\subsection{Extension I: Estimation of Ownership Costs}

The first extension modifies the benchmark model by replacing the constant discount rate $(r)$ with an exogenous and dynamic cost of ownership parameter $\left(u_{t}\right)$ in order to link expectations to asset pricing. Based on a formulation described in earlier studies (e.g., Poterba 1984; Himmelberg et al. 2005), the model estimates the annual cost 
of ownership as a function of the house price $(P)$, risk-free interest rate $\left(r^{r f}\right)$, annual maintenance rate $(\omega)$, mortgage rate $\left(r^{m}\right)$, price depreciation rate $\left(\delta^{p}\right)$, risk premium $(\gamma)$ and a constant expectation of capital gain $(E \pi)$ as shown below:

$$
u_{t}=P_{t} r_{t}^{\mathrm{rf}}(1-\mu)+P_{t} r^{\mathrm{m}}{ }_{t} \mu+P_{t} \omega+P_{t} \delta^{\mathrm{p}}+P_{t} \gamma-P_{t} \in \pi
$$

Assuming rental market clearing conditions and factoring out the price parameter, the equation reduces to:

$$
u_{t}=\frac{V_{t}}{P_{t}} \text {, }
$$

where $u_{t}$ represents the cost of ownership proposed as an alternative to the "conventional" rent-to-price ratio.

\subsection{Extension II: Heterogeneous Expectations}

In the second extension, the model allows market participants to have heterogeneous expectations. Accordingly, individuals can follow chartist and fundamentalist strategies in the estimation of the ownership cost. Chartists, who make up a constant percentage of the agent population $(\psi)$, expect the recent trends in the housing markets to continue based on the moving average of house price changes during $n^{\mathrm{m}}$ periods.

$$
E_{t}^{c} \pi=\frac{1}{n^{\mathrm{m}}} \sum_{i=1}^{n^{\mathrm{m}}} \Delta P_{t-i}
$$

On the other hand, fundamentalists, who make up the rest of the agent population $(1-\psi)$, base their expectations of the risk-free interest rate:

$$
\mathrm{E}_{t}^{f} \pi=r_{t}^{\mathrm{rf}}
$$

Hence, the market expectation for capital gain or loss resulting from housing assets in a given period equals:

$$
\mathrm{E}_{t} \pi=\psi\left(\frac{1}{n^{\mathrm{m}}} \sum_{i=1}^{n^{\mathrm{m}}} \Delta P_{t-i}\right)+(1-\psi) r_{t}^{\mathrm{rf}}
$$

With this important extension, market expectation of capital gain is no longer an exogenous input to the simulation; on the contrary, it is an endogenous component of the simulation estimated at each discrete time step. 


\subsection{Extension III: Dynamic Agent Behavior}

Finally, the third extension allows chartists and fundamentalists to switch their behaviors dynamically. The behavior-switching regime either follows Kirman's (1993) epidemiological model or Eichholtz et al.'s fitness model (2015).

In the epidemiological behavior-switching regime, there are $k$ individuals among a population of $N$ who subscribe to a certain strategy:

$$
k \in(0,1,2, \ldots, N)
$$

The system evolves as individuals meet in random where one of them recruits the other with a probability of $\rho$. In addition, individuals can change their behavior independently before meeting anyone with a small probability of $\theta$, which connotes possible self-conversion due to arrival of exogenous news. The system dynamically evolves according to a simple Markov chain based on two probabilities. The first one represents the probability of an increment from $k$ to $k+1$ after an interaction:

$$
p_{1}=\left(1-\frac{k}{N}\right)\left(\theta+\rho \frac{k}{N-1}\right) .
$$

Similarly, the second one represents the probability of a decrement by 1 :

$$
p_{2}=\frac{k}{N}\left(\theta+\rho \frac{N-k}{N-1}\right) .
$$

On the other hand, in the performance based behavior-switching regime, the following multinomial logit probability describes the percentage of agents that apply the chartist strategy:

$$
\psi_{t}=\frac{e^{\zeta f_{t}^{\mathrm{c}}}}{e^{\zeta f_{t}^{\mathrm{c}}}+e^{\zeta f_{t}^{\mathrm{f}}}}
$$

Above, the parameter $\zeta$ represents the agents' intensity of choice. At $\zeta=0$, agents do not switch their behavior, hence $\psi$ follows the initial population composition for all periods. At the other extreme, when $\zeta=+\infty$, all agents choose the strategy determined by the fitness function. Using a simpler version of the fitness measure suggested by Eichholtz et al. (2015), the proposed model assumes that agents assess the fitness of a given strategy based on the gains or losses they would incur over the $n^{\mathrm{u}}$ periods, if they had adopted a specific strategy.

The following equations show the estimation of the two fitness measures, where the fitness of the chartist strategy $\left(f_{t}^{c}\right)$ depends on the change in the log of the chartist price between two consecutive time periods:

$$
f_{t}^{c}=\frac{1}{n^{\mathrm{u}}} \sum_{i=1}^{n^{\mathrm{u}}} \Delta P_{t-i},
$$


whereas, the fitness of the fundamentalist strategy $\left(f_{t}^{f}\right)$ depends on the change in the $\log$ of the fundamental price:

$$
f_{t}^{f}=\frac{1}{n^{\mathrm{u}}} \sum_{i=1}^{n^{\mathrm{u}}} \Delta P_{t-i} .
$$

\section{Computational Representation}

In the proposed implementation of the benchmark model, housing markets evolve according to the algorithm shown in Fig. 1. This exact sequence of market activities takes place in each of the discrete time steps of the simulation for a specified number of iterations. For the first step, the values of stock, rent, price, and construction activity are simply equal to their initial values. For the subsequent ones, following Eq. (3), current stock levels increase or decrease depending on the quantity of depreciated stock and on the quantity of delivered housing. With this new stock level, rents adjust according to the market clearing conditions assumed in Eq. (2). Then, prices of housing units reflect the changes in rents using Eq. (5); and this stimulates further construction activity delivered in the future, following Eq. (4).

While the previous sequence mainly describes the benchmark model, the proposed model differs by allowing agent heterogeneity in the portion of the diagram shaded with gray. This portion is further delineated in Fig. 2.

As shown in Fig. 2, in a housing market consisting of a representative agent, prices depend on ownership costs estimated with a constant expectation of capital gain. In contrast, in a housing market consisting of heterogeneous agents, prices have a fundamental component and a chartist component. The estimation of the fundamental component is straightforward: fundamentalist agents simply determine the price based on current ownership costs estimated with expectations that match the risk-free interest rate. On the other hand, if there are at least two past observations that chartists can extrapolate from, chartist expectations affect prices too. Furthermore, in this case, depending on the simulation parameters, agents may update their behavior dynamically based on a behavior-switching regime. Thus, market prices reflect the fundamental and chartist components weighted by their respective percentages in the agent population.

\subsection{Details of Model Implementation}

The simulation proposed in this study implements The Microsoft Office Excel@ Visual Basic for Applications (VBA) object model using a computational design pattern known as Model-View-Controller (MVC). Following this pattern, the "Model" module encapsulates the underlying logic of the simulation; the "View" module handles user interface and charting functions; and the "Control" module coordinates the program flow. As shown in Fig. 3, the model module primarily consists of a singleton object that encapsulates simulation parameters and several markets. As part of the view module, each of the markets has a corresponding dashboard used in "stepping through" the evolution of price and stock formation during the simulation runs. 


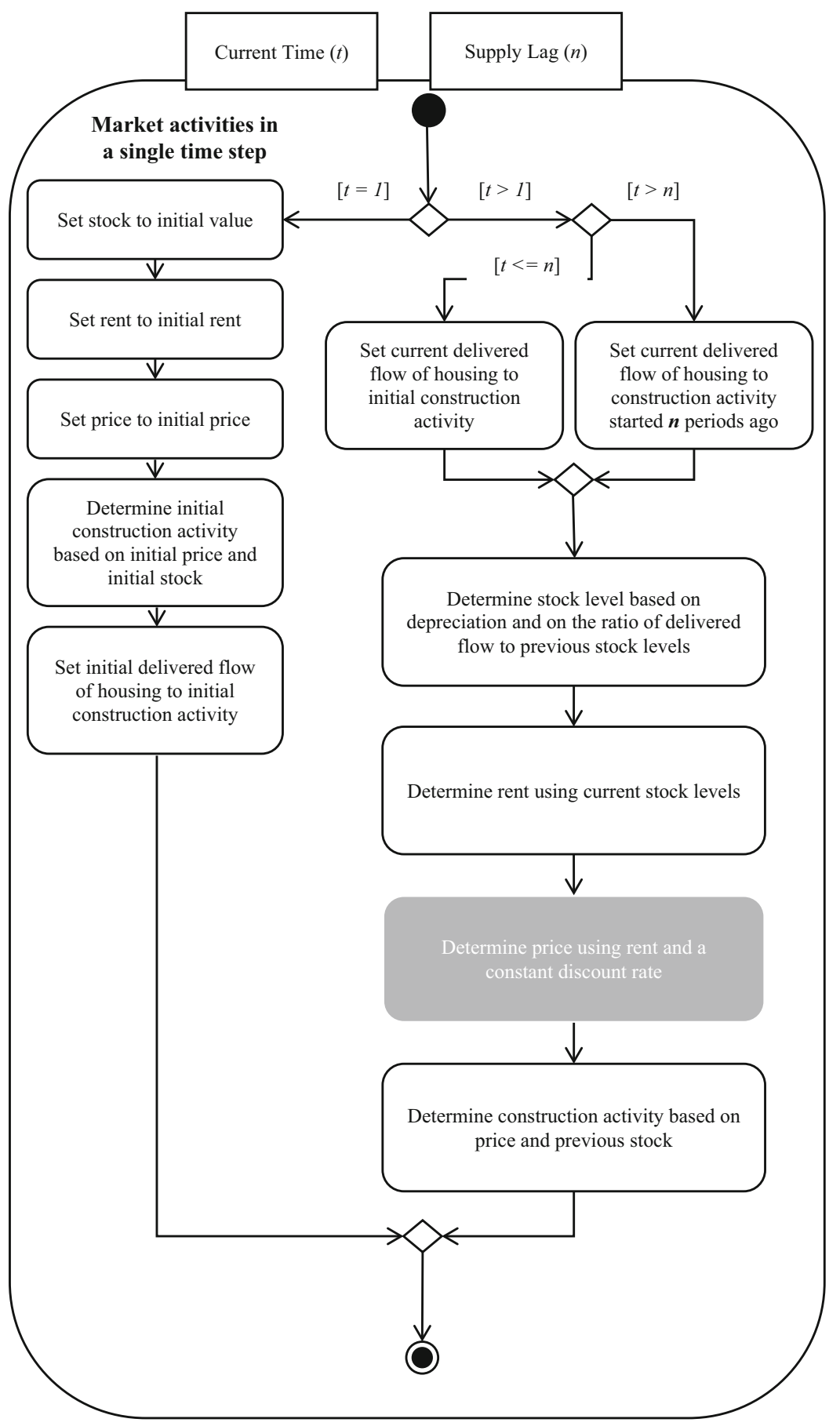

Fig. 1 Housing market activities in each time step of the simulation shown with an activity diagram in UML (Unified Modeling Language) 


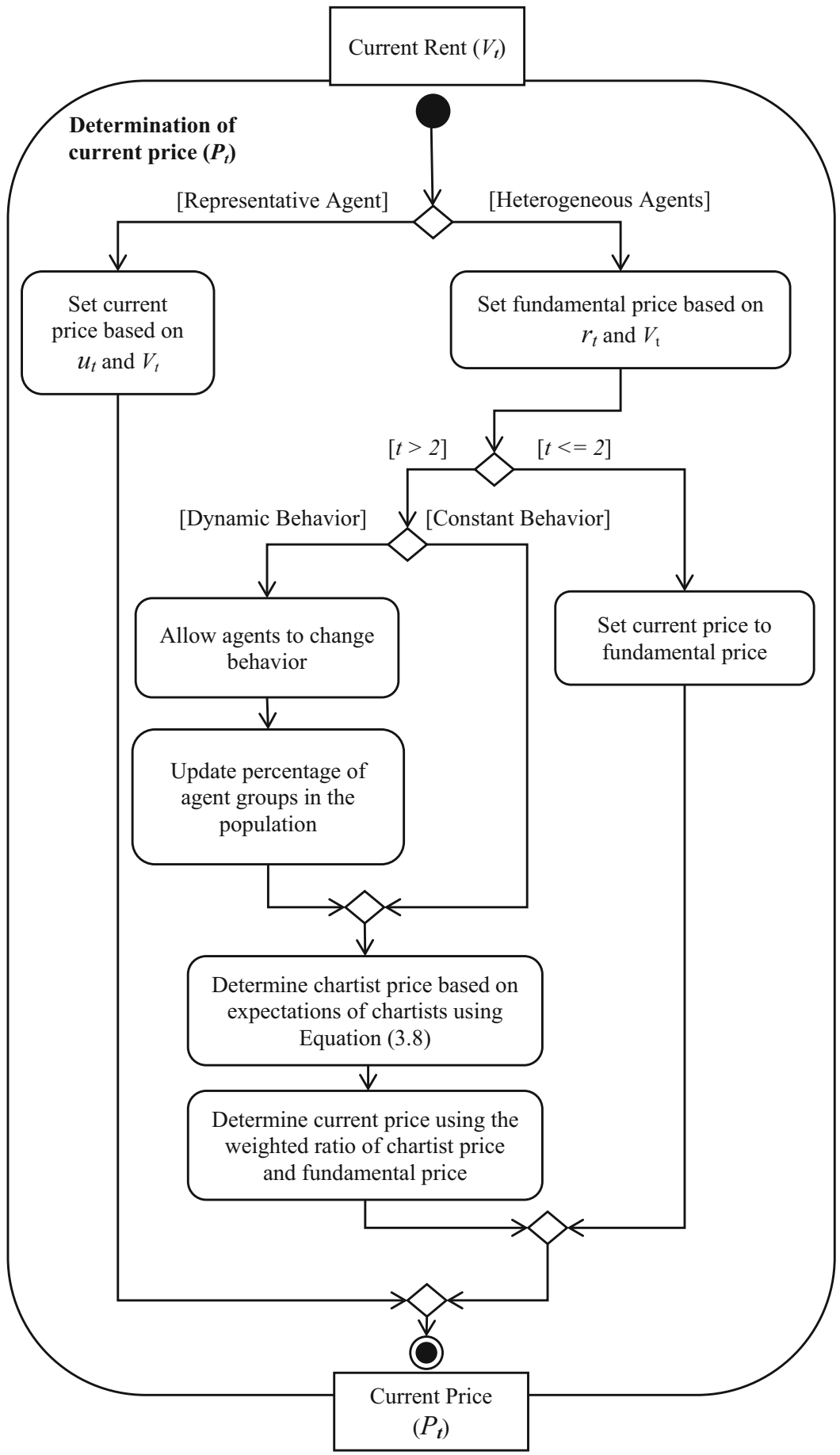

Fig. 2 Price determination algorithm of the proposed model shown with an activity diagram in UML 


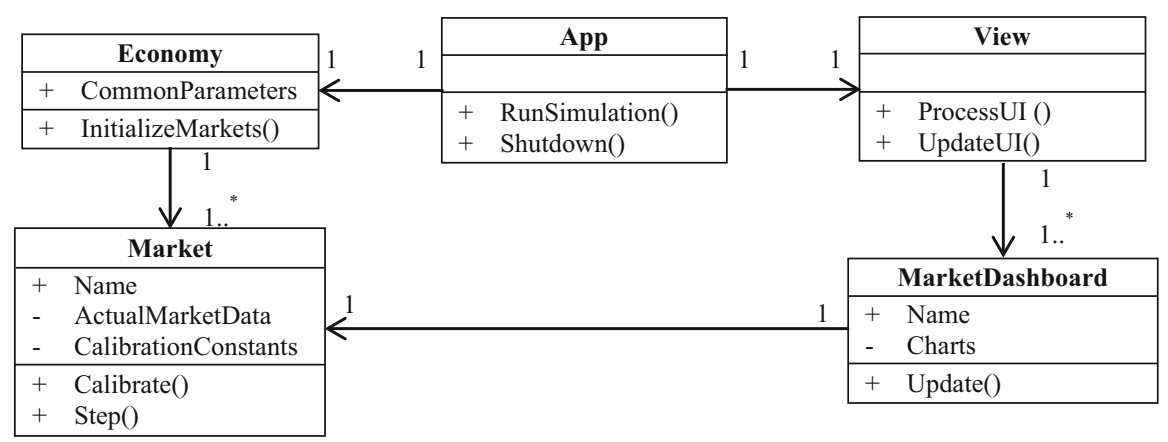

Fig. 3 Class relationships in the simulation

The view module (shown in Fig. 4) contains user interface dialogs, which facilitate model initialization. Users of this interface can observe the evolution of market phenomena in a stepwise fashion with the dashboard shown in Fig. 5.

\section{Verification and Experimentation}

This section presents the verification of the proposed model. As suggested by LeBaron (2001), the verification starts with a comparison of the simulation results to the known behavior of the benchmark model. It then proceeds to experiment with model extensions presented previously in Sects. 2.2, 2.3 and 2.4.

\subsection{The Benchmark Model}

Running the simulation dynamically yielded patterns that are identical to published results (Wheaton 1999). In the specific example shown in Fig. 6, an increase of 50\% in the demand instrument $(E)$ shocks the housing market. This generated an immediate response in prices followed by fluctuations in both prices and stock. Since the discount rate is constant, prices moved in tandem with rents.

It is possible to use the model for experimentation. For example, an interesting question is to ask how housing prices and stock evolve over time when demand does not increase abruptly but increases steadily to the post-shock levels over time. As shown in Fig. 7, in this case, price fluctuations were much milder, and the increase did not dissipate as early as the former case. Furthermore, stock formation did not display any fluctuations, but increased in parallel to increasing demand. Like the previous case, changes in rents and changes in prices moved in tandem.

\subsection{Extension I: Effects of Dynamic Ownership Costs}

As stated earlier, the proposed model modifies the benchmark model by replacing the constant discount rate $(r)$ with an exogenous and dynamic cost of ownership parameter $\left(u_{t}\right)$ to link expectations to asset pricing. The next set of simulations holds the demand 
Fig. 4 The user interface dialogs of the simulation used in initialization
Kale-Ozbakan Housing Market Simulation Initialization $\times$

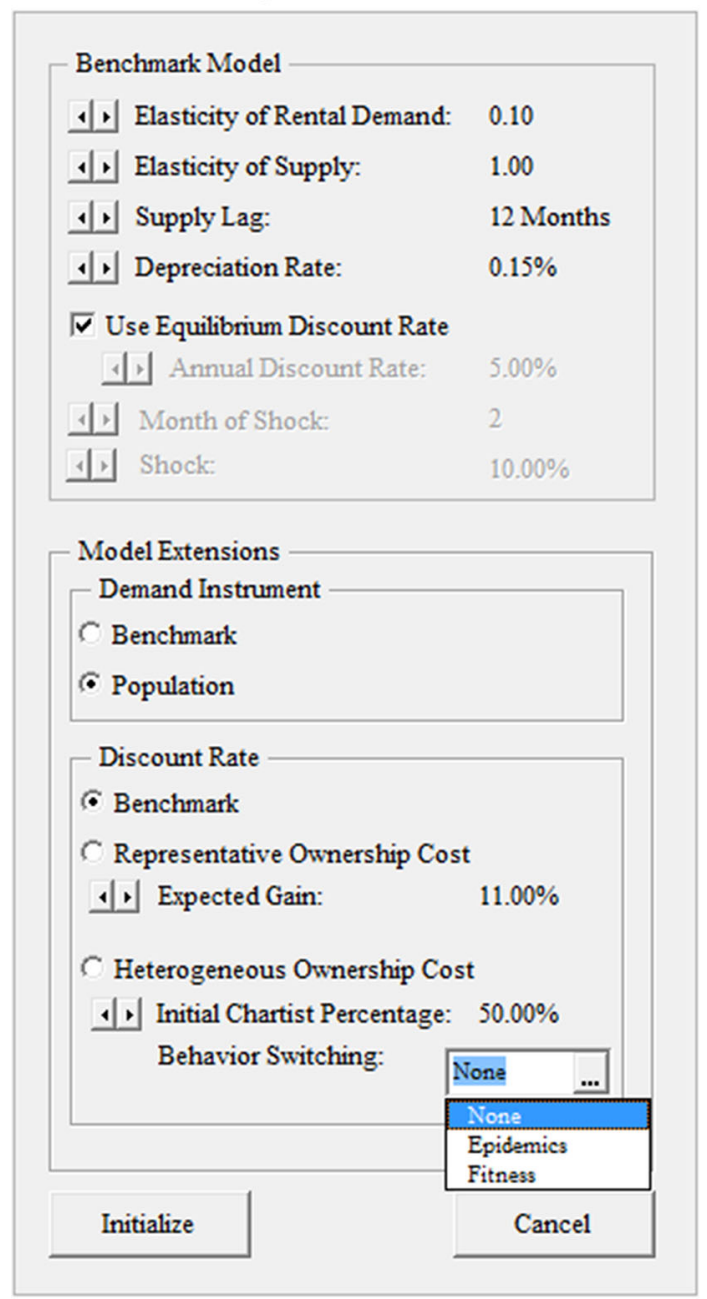

for rental space $(E)$ constant while experimenting with gradual declines in ownership costs $(\Delta u)$. As shown in Fig. 8, housing markets are quite sensitive to such a change. Notably, the same fluctuations created by the changes in demand are visible with changes in ownership costs. As expected, with a decline in ownership costs, rents and prices did not move in tandem anymore; on the contrary, they moved in opposite directions. Especially for changes that exceed $2 \%$, the price model exploded, leading to excessive stock formation and sharp declines in rents.

Because the underlying model displays distinct patterns with different elasticity parameters, it is also instructive to observe the effects of changes in ownership costs against such market fundamentals. For this purpose, Fig. 9 charts the output from several combinations of price elasticity of rental demand $(\varepsilon)$ and price elasticity and supply $(\eta)$. 


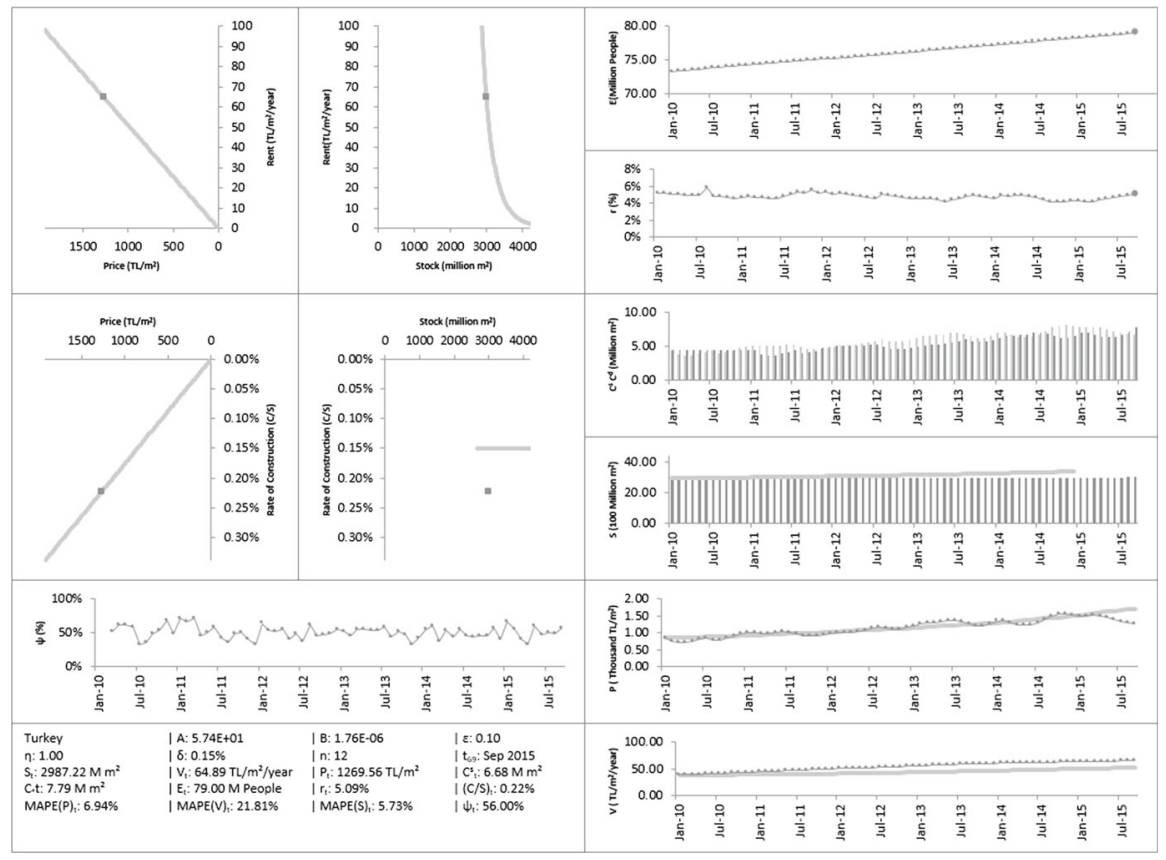

Fig. 5 The simulation dashboard showing the four quadrants of the benchmark model and time series charts of population, discount rates, started and delivered flow, stock, price, rents and percentage of chartist agents
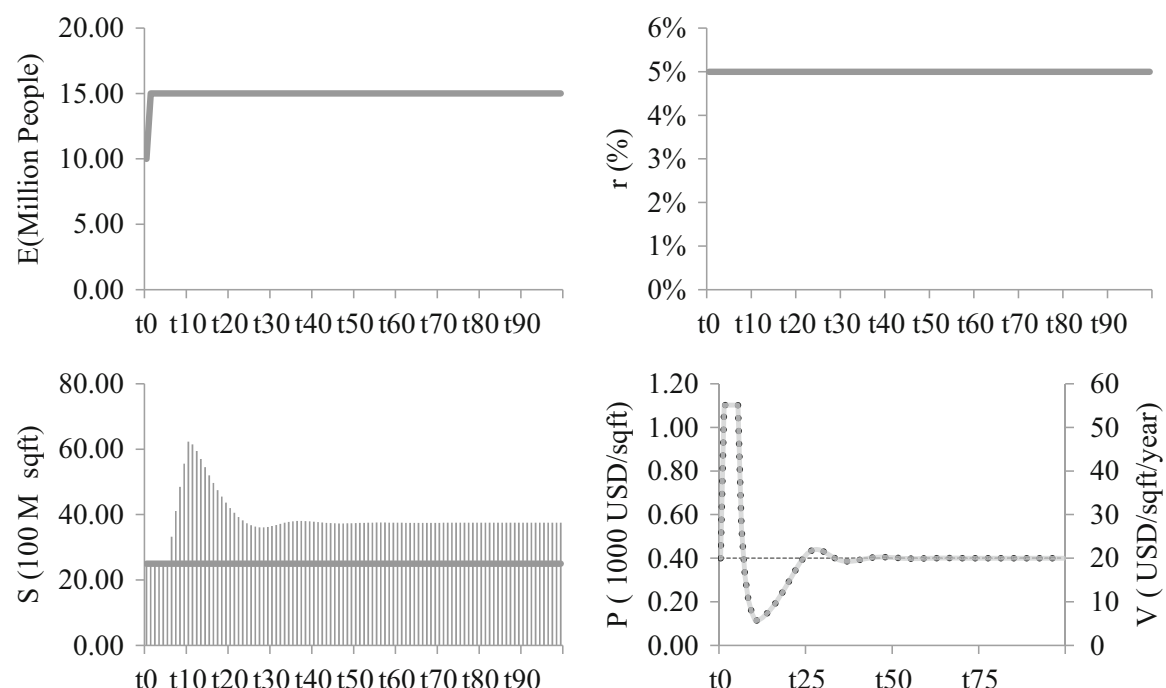

Fig. 6 Verification: Model behavior with $\varepsilon=0.4, \eta=2, \delta=0.05$ and $r=0.05$

The results were in line with neoclassic theory. In markets with inelastic supply and elastic demand (i.e., $\varepsilon=2.00, \eta=0.50$ ), gradual changes in discount rates caused price increases that are explosive; at the opposite end, with elastic supply $(\varepsilon=0.40$, $\eta=2.00$ ), prices followed a stable pattern. 

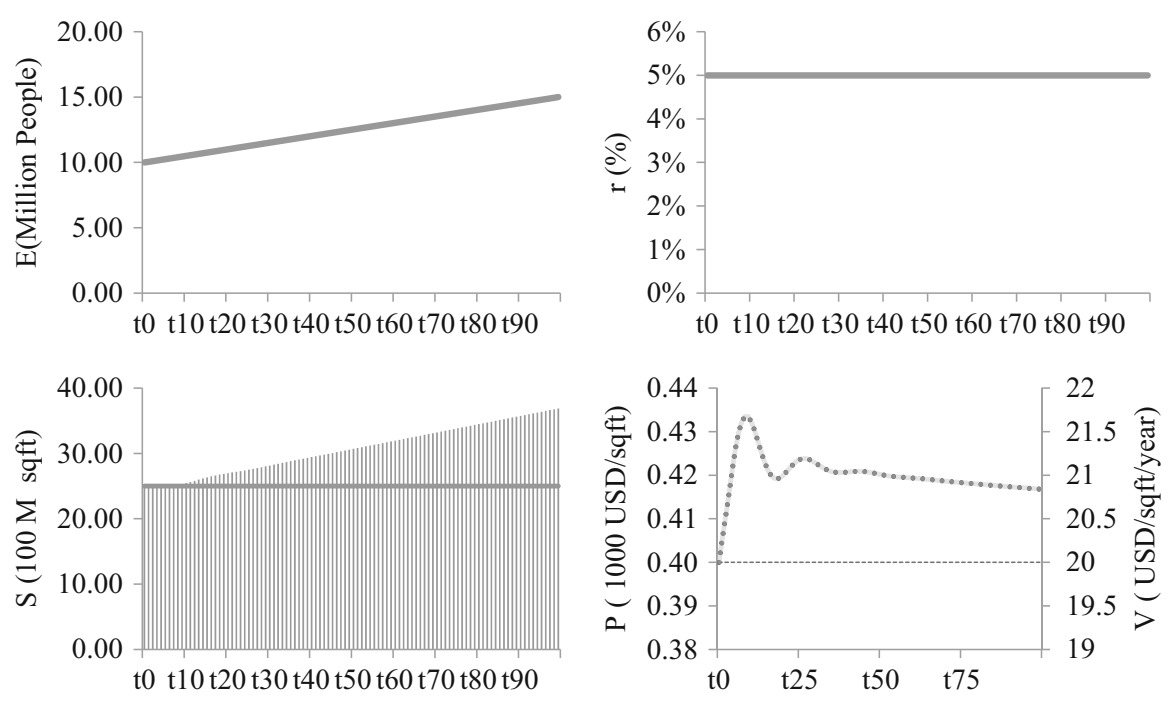

Fig. 7 Experimentation: Model behavior showing effects of demand increase spread over time
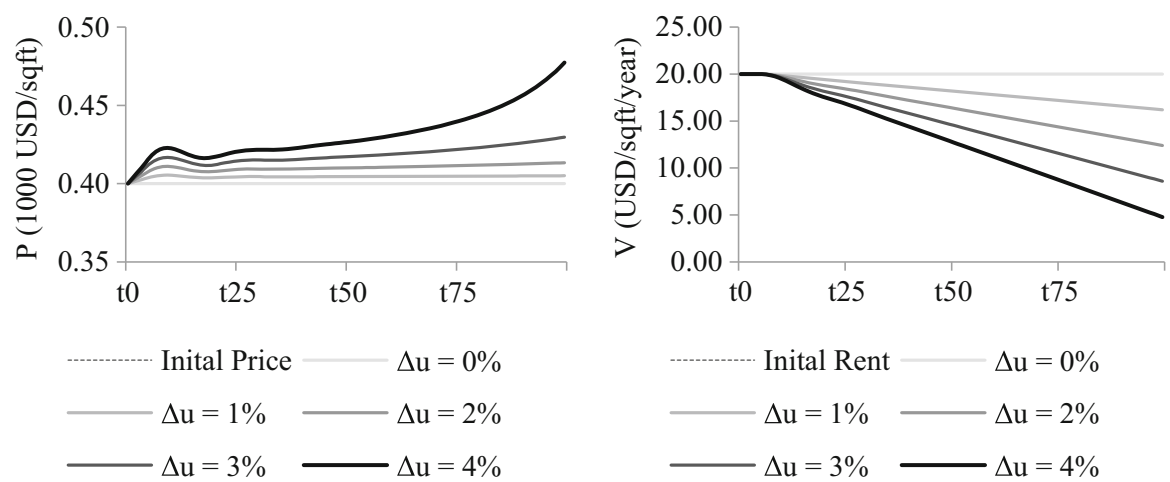

Fig. 8 Sensitivity analysis of changing ownership costs $(\Delta E=0)$

During the verification of the other extensions to the model, the parameters shown in Table 1 remain constant. This allows analyzing the effects of further modifications ceteris paribus while focusing on the effects of endogenously changing ownership costs.

\subsection{Extension II: Effects of Heterogeneous Expectations}

The second extension allows market participants to have heterogeneous expectations. Accordingly, individuals in the following experiments can follow chartist and fundamentalist strategies in determining the housing prices. In order to gauge this effect, experiments I, II and III in Fig. 10 simulate a market where ownership costs decrease gradually for $2 \%$. In this setting, market behavior followed the fundamentals strictly, 

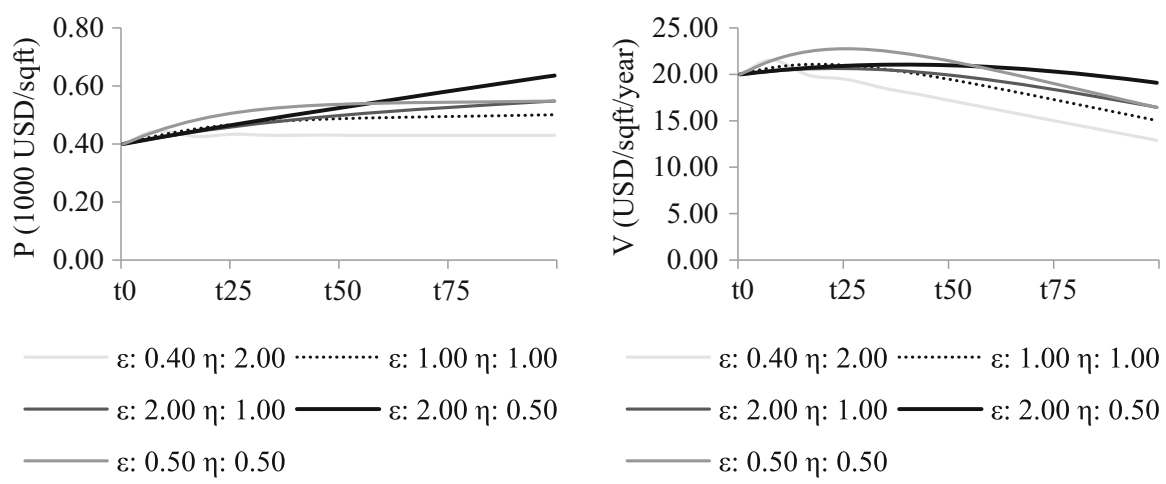

Fig. 9 Sensitivity analysis of changing ownership costs and elasticities (The change in rental demand $(\Delta E)$ is $50 \%$ and the change in ownership costs $(\Delta u)$ is $2 \%$.)

Table 1 Parameters that remain constant in subsequent model extensions

\begin{tabular}{lll}
\hline Parameter & Symbol & Value \\
\hline Change in demand instrument & $\Delta E$ & $0 \%$ \\
Change in user costs & $\Delta u$ & $2 \%$ \\
Price elasticity of rental demand & $\varepsilon$ & 1 \\
Price elasticity of supply & $\eta$ & 1 \\
Stock depreciation rate & $\delta$ & $1 \%$ \\
Memory for price extrapolation & $n^{m}$ & 2 \\
Memory for strategy comparison & $n^{u}$ & 2 \\
Supply lag & $n$ & 5 \\
\hline
\end{tabular}

with the maximum price reaching up to $561.70 \mathrm{USD} / \mathrm{sqft}$. Similarly, experiments IV, $\mathrm{V}$, and VI simulate a market where ownership costs decrease for $2 \%$, but this time abruptly. In a fundamentalist-only market generated in experiment IV, the maximum price reached $666.66 \mathrm{USD} / \mathrm{sqft}$. Noticeably, such an increase in prices did not occur in experiment $\mathrm{V}$ where chartists made up the entire population of the market, i.e., $\psi=100 \%$. However, when the market comprised both groups, the price went as high as $771.78 \mathrm{USD} / \mathrm{sqft}$, "overshooting" the fundamental price as expected.

Two observations summarize these experiments. First, the presence of chartists affects the market outcome dramatically when the exogenous shock is sudden. More importantly, the presence of chartists alone does not lead to elevated prices; their impact is only visible when there are fundamentalists who react to the exogenous changes on market fundamentals.

\subsection{Extension III: Effects of Dynamic Agent Behavior}

In the third extension, the proposed model allows heterogeneous agents to interact with each other. It does so by implementing (1) Kirman's (1993) epidemiological model and (2) Eichholtz et al.'s (2015) fitness model as two distinct behavioral switching regimes. 


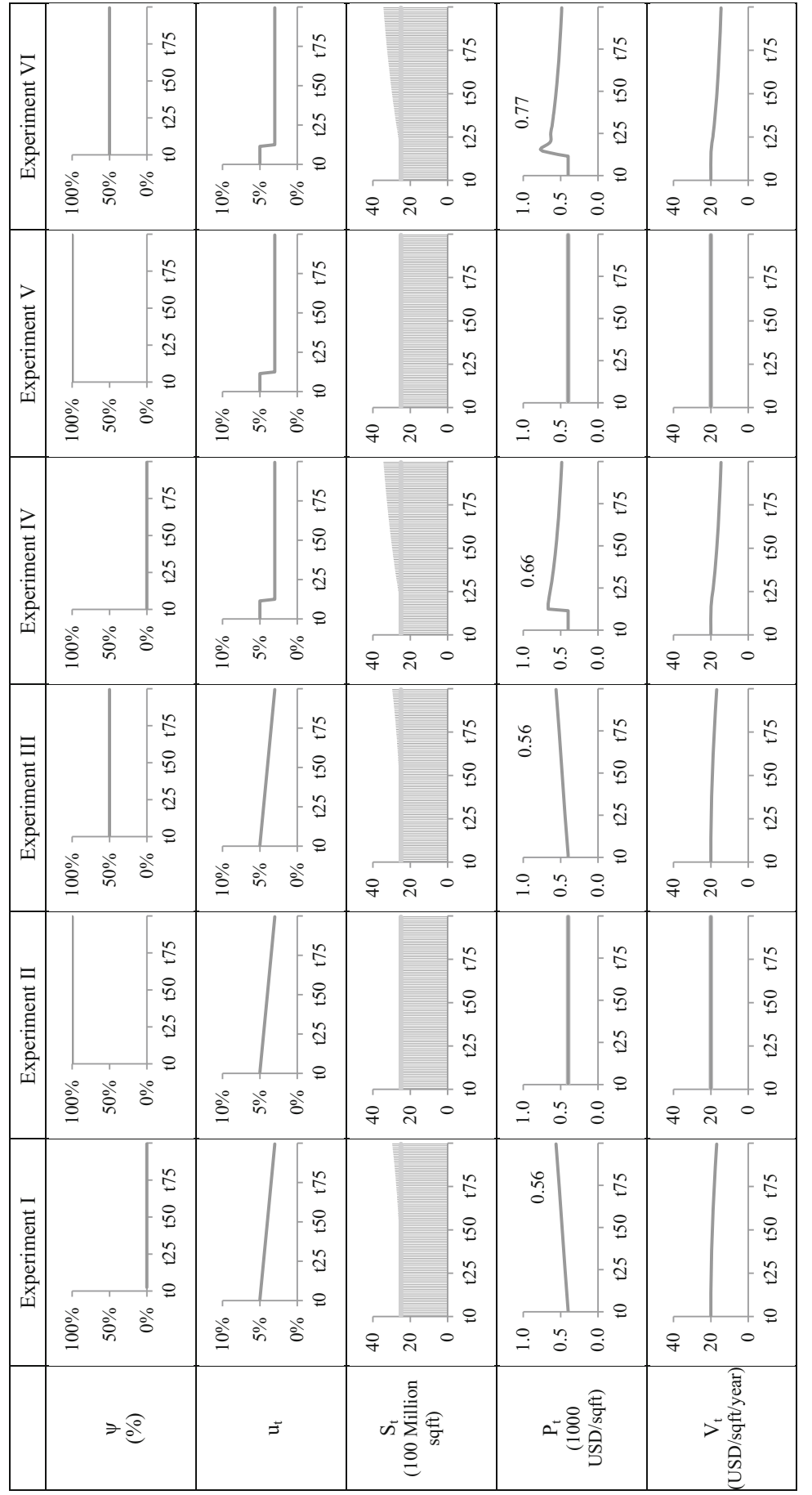

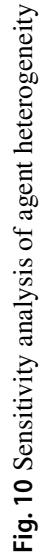


In the epidemiological behavioral switching regime, house prices evolve as one of the fundamentalist or chartist individuals recruits others with a probability of $\rho$. In addition, prices reflect self-initiated changes in behavior, which occur with a probability of $\theta$. As discussed earlier, the model produces three noteworthy frequency distributions depending on the values of $\rho$ and $\theta$. In the first case, the percentage of chartists and fundamentalists remain around one half of the population. In the second one, the percentages of agents are uniformly distributed. Finally, in the third case, both groups take either very high or very low values, simulating the presence of a "large majority" in the population.

In Experiment I, where chartist and fundamentalists consistently make up around one-half of the population, prices fell steadily after the initial price rise. In Experiment II, agents recruit each other with relative ease and their distribution in the population was uniform over time. In such an experimental setting, prices began to fluctuate, but the change in magnitude was not extreme. In contrast to the previous experiments, when majority groups dominate the market, the price behavior changed drastically. For example, fluctuations had magnitudes that are unmatched in previous experiments; furthermore, the frequency of fluctuations was higher, causing the price instability to persist until later periods.

In the behavior-switching regime based on fitness, agents consider the past performance of alternative strategies in determining their current behavior. As shown in Fig. 11, in Experiment I, when the intensity of choice parameter $\zeta$ is zero, agents maintained their initial positions no matter what happens in the housing markets. In this scenario, following the shock in the 12th period, prices went up only modestly and gradually fell back to its steady state. In Experiment II, agents are mildly sensitive to the capital gains and losses of others. As such, only a small group of chartists changed their behavior when they observed the gains that the fundamentalist strategy would have produced with the fall in ownership costs. Again, the change in prices was relatively low. In Experiment III, market participants began to switch to the alternative strategies en masse. More importantly, the price changes in the final experiment dwarfed the previous results. With successive swings in the market sentiment, the maximum price level went up as high as $500 \%$.

The purpose of experimentation was to ensure that the model works as intended. As various outputs from the model demonstrated, the proposed model produces identical behavior to that of the benchmark model. Furthermore, the model produces expected behavior in line with neo-classical theory in the experimentation with changes in dynamic ownership costs, and with behavioral theory in the experimentations with heterogenous expectations and dynamic agent behavior.

\section{Validation}

This section presents the validation of the proposed model by comparing the simulation results to the actual data collected from Istanbul's housing market between January 2010 and September 2015. During this period, as shown in Fig. 12, inflation adjusted real house prices increased dramatically in the city. 


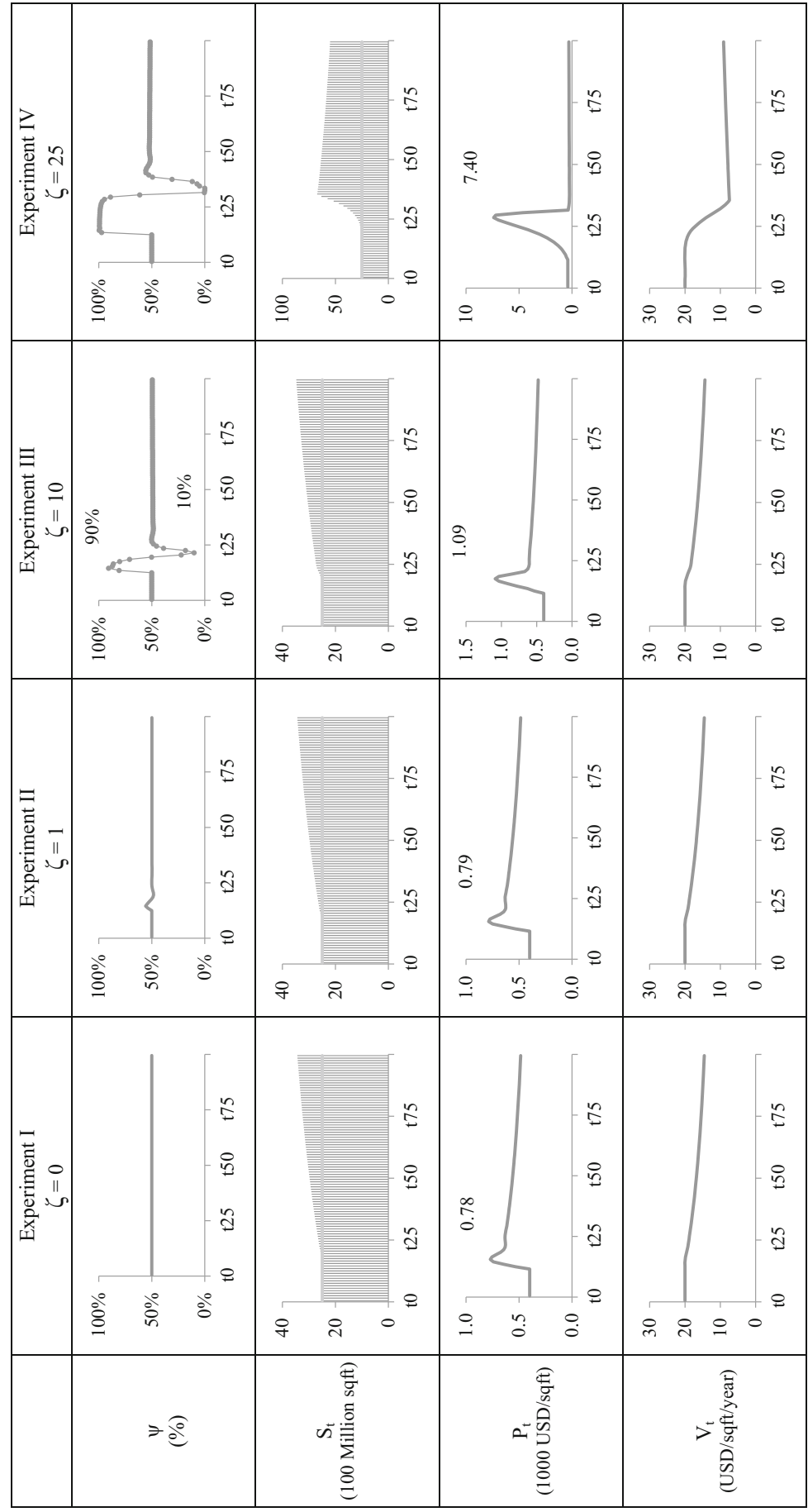

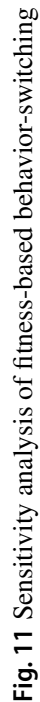




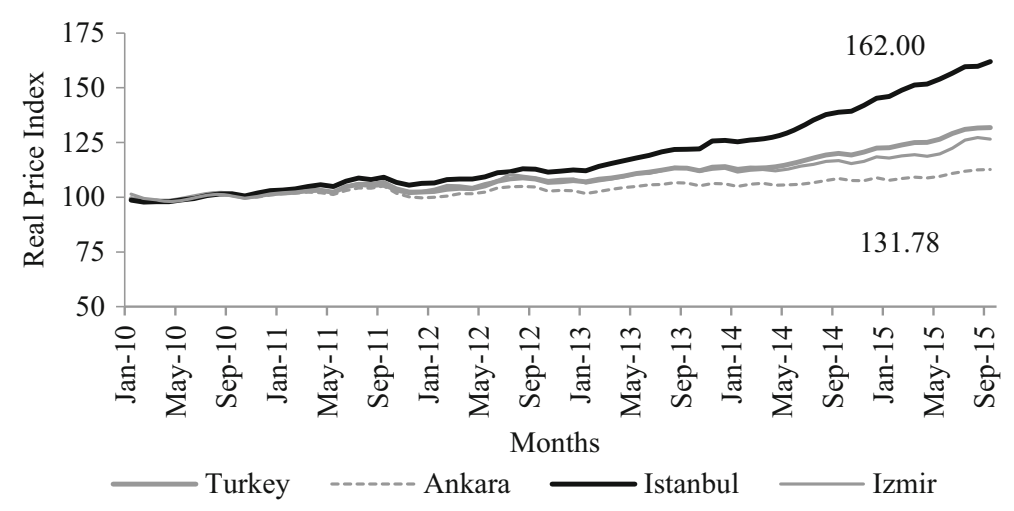

Fig. 12 Comparison of the real house prices in Istanbul to other national markets. (Sources: "House Price Index", Central Bank of the Republic of Turkey; “Consumer Price Indices”, Turkish Statistical Institute)

The validation consists of three sets of experiments. The first set utilizes parameter values that generate unstable market behavior in the benchmark model, whereas the second set utilizes parameter values that converge to a steady state. Based on these observations, the third set of experiments specially focus on parameters which seem to affect model substantially, namely the memory of chartist agents $\left(n^{m}, n^{u}\right)$ and the intensity of choice parameter $(\zeta)$. For comparison purposes, a simple statistic known as mean absolute percentage error (MAPE) is used, which expresses accuracy of the simulation model as a percentage error:

$$
\left(\frac{1}{n} \sum_{t=1}^{n}\left|\frac{e_{t}}{A_{t}}\right|\right) * 100 .
$$

where $A_{t}$ is the actual price, rent, or stock levels; and $e_{t}$ is the difference between $A_{t}$ and the simulated price, rent or stock level for a given period. It is important to note that the intention here is not to minimize this metric but to use it as a tool in observing the model's aggregate behavior.

Tables 2 and 3 show the first and second set of experiments. Although the two sets differ in terms of the underlying price elasticities, they exhibited similar patterns regarding the gradual introduction of behavioral parameters. In both sets, Experiment I provides the benchmark conditions with a constant discount rate, and Experiments II and III introduce the dynamic ownership costs. As it is noticeable in the tables, the results were quite sensitive to the expected rates of capital gain, since a difference of $0.5 \%$ in expectations (i.e., from $10 \%$ to $10.5 \%$ ) changed the MAPE for prices around 5\%. Next, experiments IV, V and VI demonstrate the effects of introducing heterogeneity into the market. In both sets of experiments (i.e., with unstable elasticity parameters and stable elasticity parameters), allowing heterogeneous behavior among market participants improved the performance of the price model significantly. It is also interesting to note that the variation of the chartists' percentage from $25 \%$ to $50 \%$ and $75 \%$ did not seem to have an observable effect on the performance of the model. Furthermore, utilizing a behavior-switching regime based on 


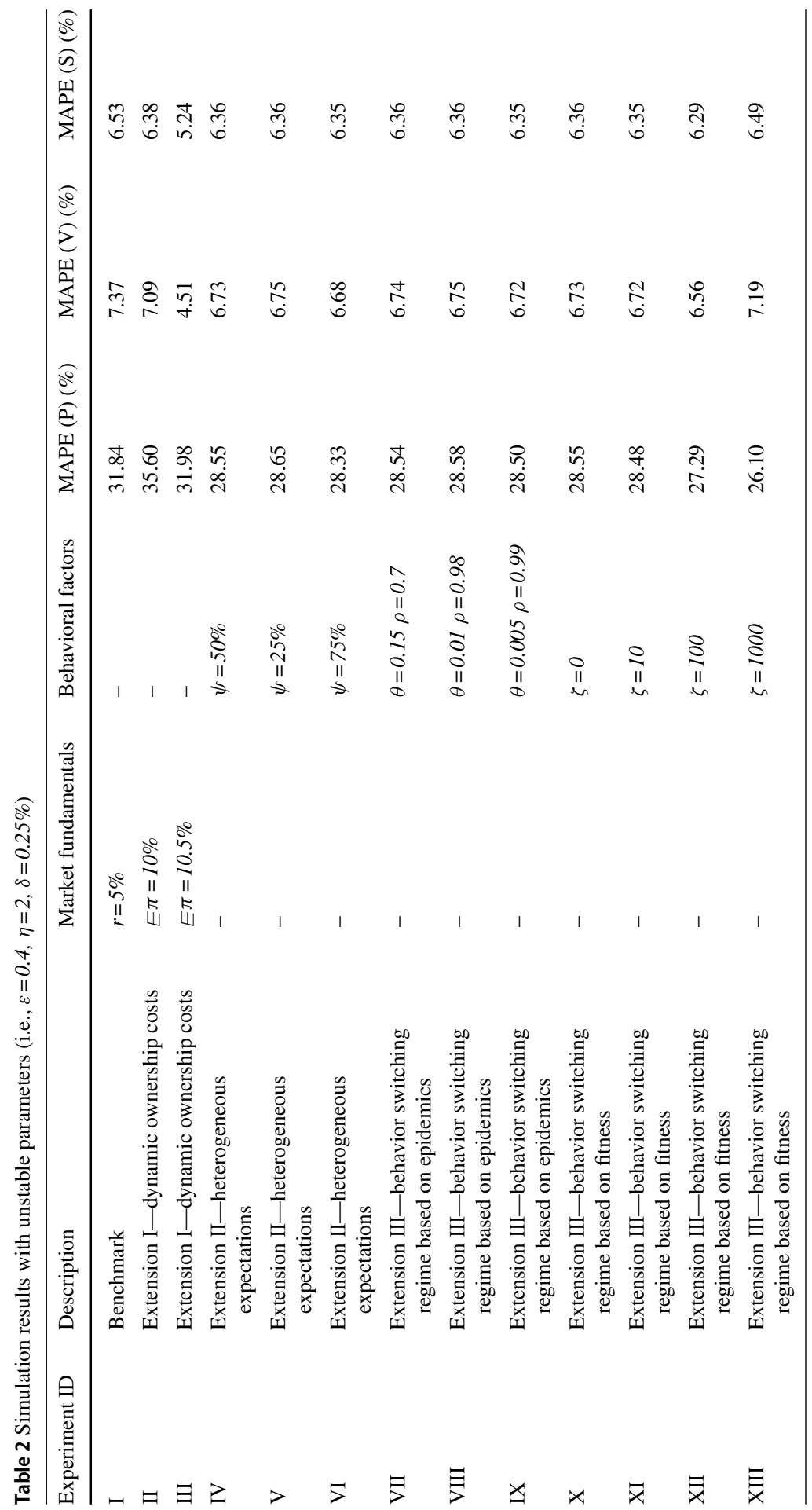




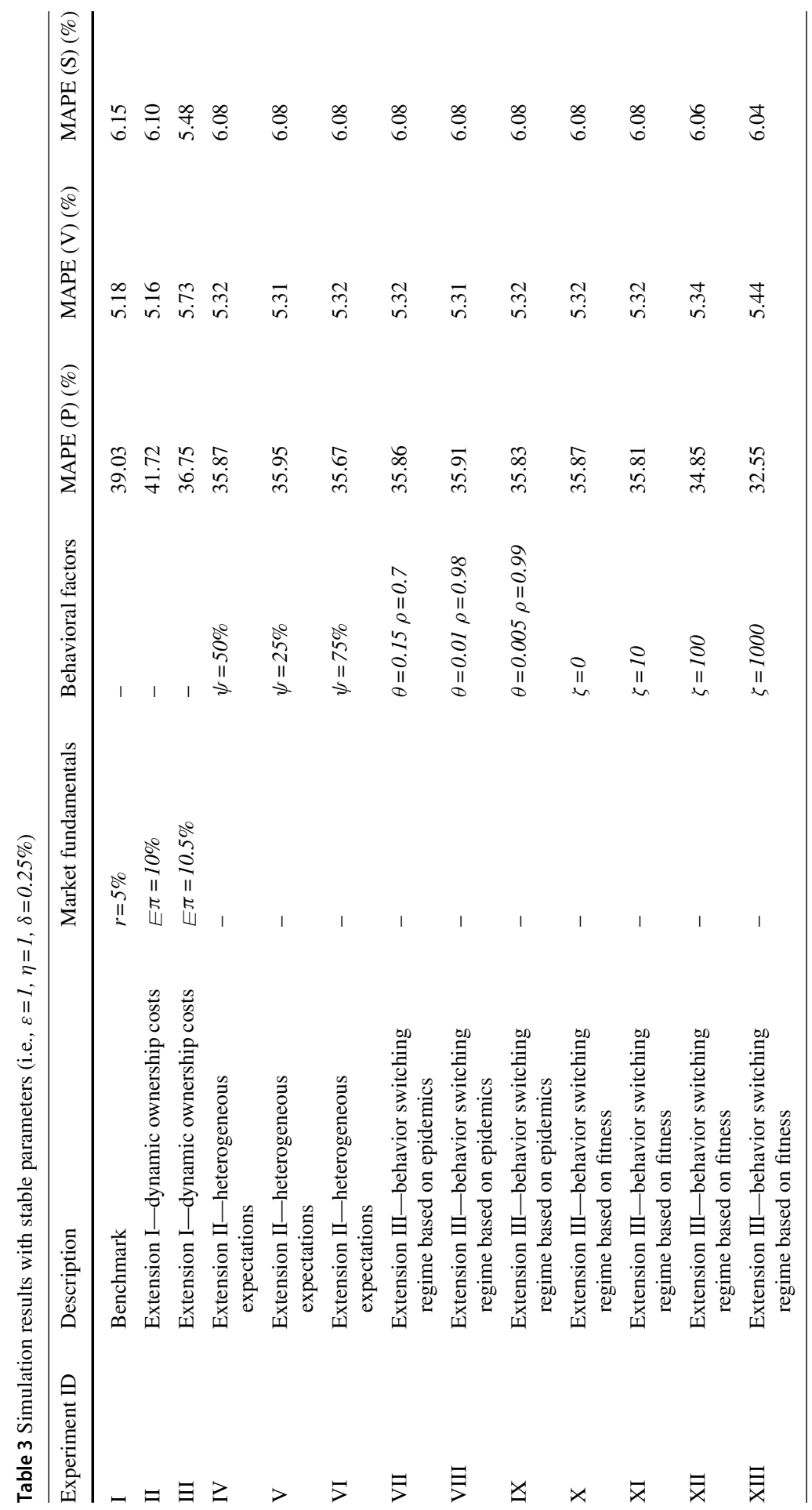




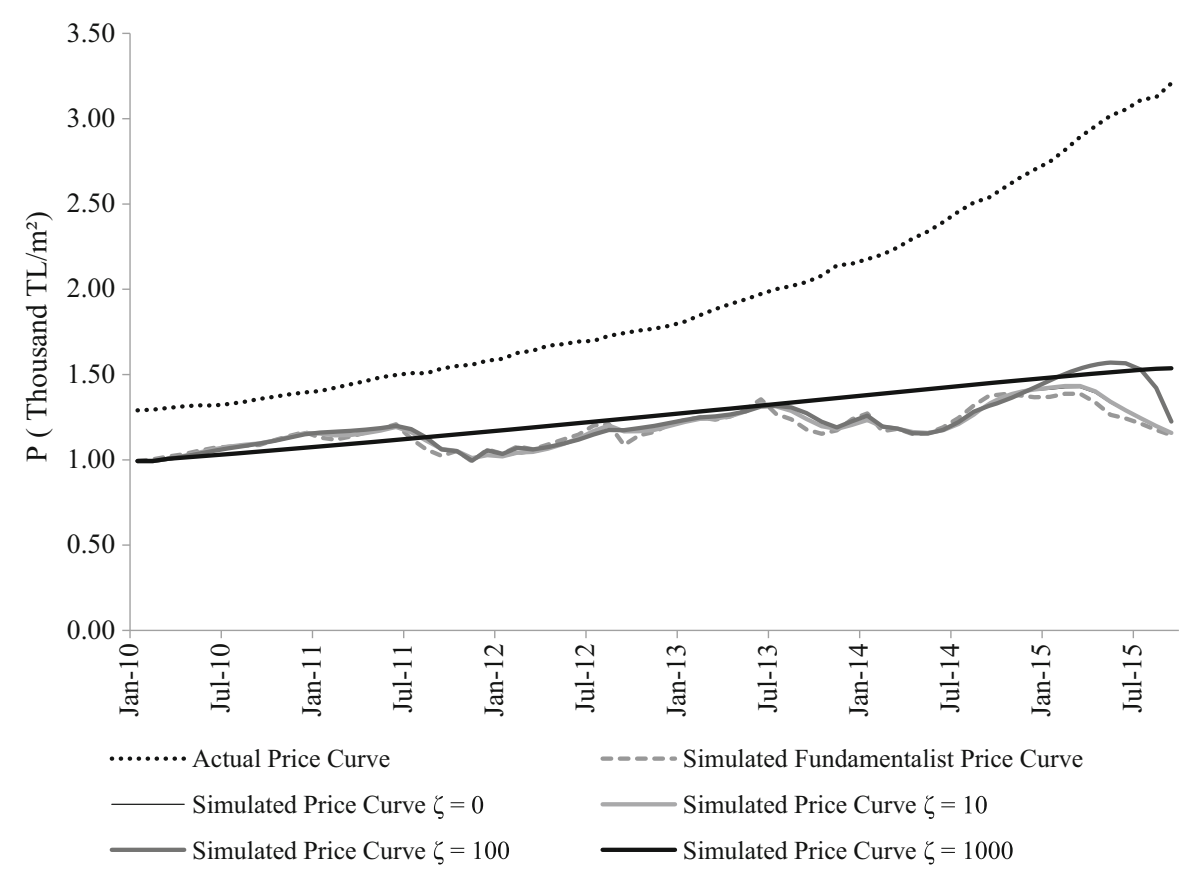

Fig. 13 The effects of "intensity of the choice" on price dynamics $(\varepsilon=1, \eta=1$ and $\delta=0.25 \%)$

epidemics did not improve the performance of the model. As experiments VII, VIII, and IX demonstrate, various combinations of recruitment and self-conversion brought about almost identical results to those obtained from the previous versions of the model.

However, starting with experiment XII, the MAPE for prices began to decrease observably. As Fig. 13 shows, this can be explained by the sensitivity of the model to the intensity of choice parameter included in the fitness-based switching regime. Especially, when the parameter took values as high as 1000 , market price began to deviate from the fundamental price and followed a steadily increasing trend.

To understand this trend formation, it is instructive to see how the percentage of chartists changes with respect to $\zeta$. As Fig. 14 depicts, increasing this parameter from 100 to 1000 allowed chartists tendencies to take over the market entirely. Thus, the market disconnected from the underlying fundamentals and prices increased on a steady basis.

Aside from the improvement in error metrics, there is another noteworthy observation in Figs. 13 and 14 pertaining to the introduction of the fitness-based behavior-switching regime. With values of 10 and 100 for $\zeta$, the proposed model displayed endogenous price fluctuations similar to those that are reported in related literature (e.g., Bijman 2012; Dieci and Westerhoff 2012; Bolt et al. 2013; Campisi et al. 2018). This raises the possibility of chaotic motion in price formations under the specific settings of this paper and implies instability in the market even with stable parameter settings for the underlying benchmark model. 

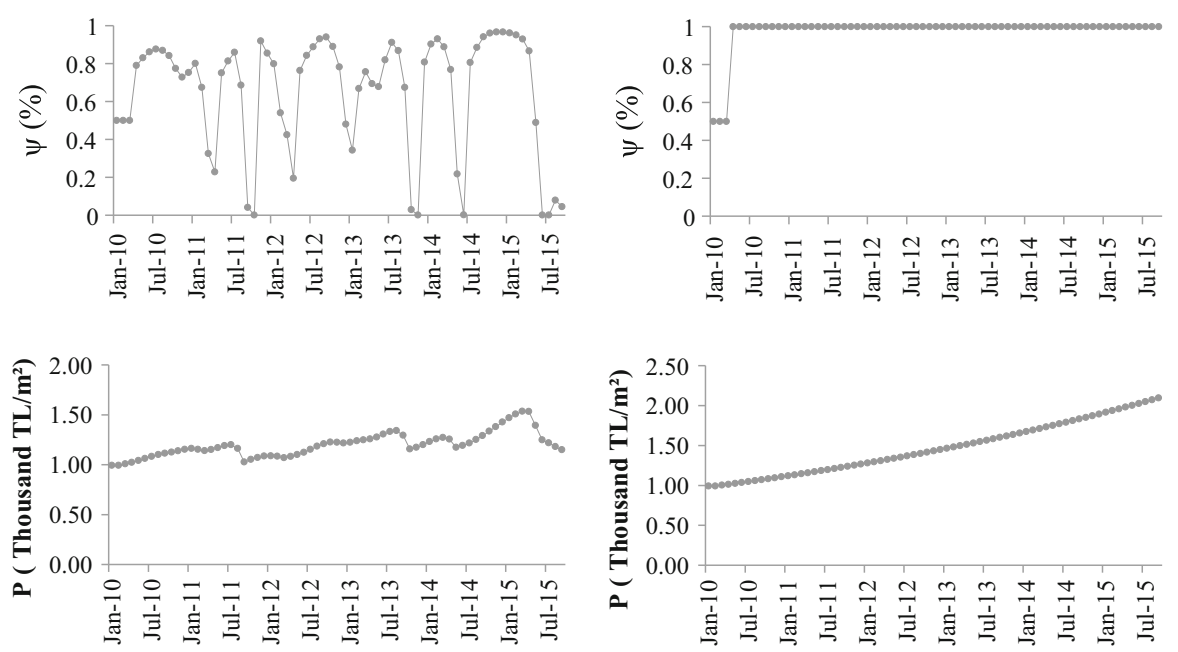

Fig. 14 The effects of "intensity of the choice" on heterogeneity and price formation (Left chart $\zeta=100$, right chart $\zeta=1000$ )

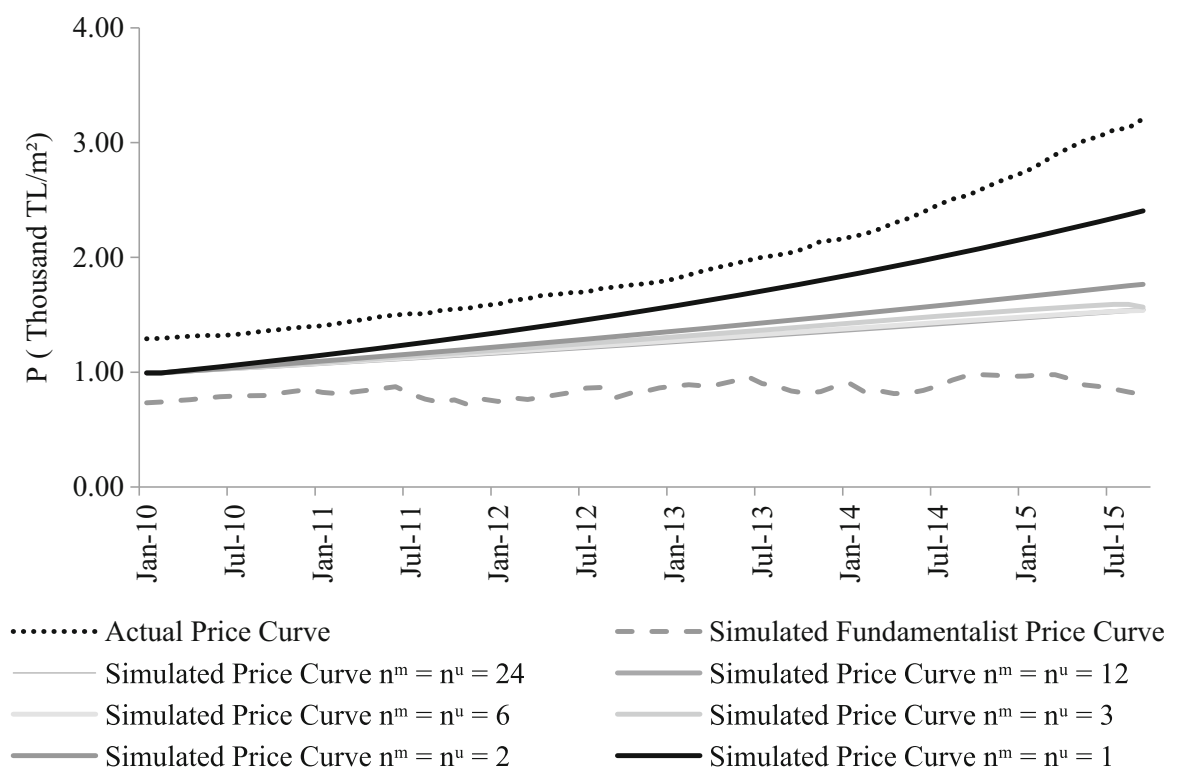

Fig. 15 The effects of the market participants' memory on price formation

Further analysis of the model revealed that the market trend is highly sensitive to the time frame that participants use in extrapolating future prices $\left(n^{m}\right)$ as well as the time frame they use $\left(n^{u}\right)$ in comparing the competing strategies. Precisely stated, as the memory of the market participants got shorter, the price trend became steeper. Figure 15 conveys the same information visually. As investor myopia increased (i.e., as the number of months used in extrapolation and strategizing decrease), simulated prices deviated from the fundamentals and began to mimic the actual trend. 
In summary, the results of the validation process suggest that the price dynamics in the market examined in this study cannot be simulated by using economic fundamentals alone. In other words, relying solely on automatic adjustment of prices based on supply and demand forces yields an incomplete picture for the observed price increase in the market. However, such a model can be improved by introducing behavioral heterogeneity and allowing agents to switch their market preferences over time.

\section{Conclusions}

This paper demonstrated that incorporating insights from behavioral economics in an agent-based model can be helpful in the exploration of price formations in housing markets. For this, the study utilized a prominent real estate model for benchmarking purposes and gradually extended it to include ownership costs (Extension I) and behavioral insights (Extensions II and III). As demonstrated in the verification section, the extended model produced expected behavior in line with neo-classical theory in the ownership cost experiments, and with behavioral theory in the related experiments.

Next, using Istanbul's housing market as the empirical context, we initially showed that the benchmark model based on market fundamentals only (i.e., price elasticity of rental demand, population growth, discount rate, supply lags, price elasticity of supply, and depreciation rate) does not generate the observed actual price pattern. Then, using the behavioral extensions, we specifically focused on two interrelated questions: To what extent does the inclusion of (1) behavioral heterogeneity and (2) dynamic market behavior enhance the benchmark model?

Our findings suggest that extending the model to allow behavioral heterogeneity brings about a significant improvement in comparison to the benchmark model. Regarding the inclusion of dynamic market behavior, the results show that extending the model with an epidemiological behavior-switching regime does not improve the model. In contrast, extending the model with a fitness-based behavior-switching regime gradually brings about improvement. The performance of such a model is quite sensitive to the length of the past observations that market participants consider in making pricing decisions. In summary, the model produces the most favorable results when there are agents with extremely myopic expectations in the market and when other agents mimic them.

These findings support studies that call for an agent-based approach in exploring house price dynamics. However, it is important to note that the potential of heterogeneous models lies in allowing market participants to interact with each other. In other words, heterogeneity in and of itself does not seem to make a substantial difference unless the agents can update or switch their behavior dynamically.

The findings of the model may have policy implications. Since the model can generate endogenous price fluctuations, policy makers may adjust the structural parameters such as interest rates or elasticity of supply to prevent instability. Furthermore, even with parameter settings that do not yield complex dynamics, they may use the model to gauge the deviation of market price from fundamentals. 
This study can pave the way for future studies in a variety of ways depending on the interests and the backgrounds of researchers. Since the proposed model in this study is capable of generating endogenous price fluctuations, researchers with expertise in evolutionary dynamics can focus on the proposed model's stability analysis by utilizing state of the art tools such as bifurcation diagrams and phase plots. Similarly, researchers interested in the micro foundations of economic modelling can introduce further heterogeneity to the agent-based model and experiment with a variety of techniques ranging from game-theoretical approaches to the evolutionary selection of expectation rules. Another direction would be to extend the research by focusing on the estimation of the underlying parameters of the model (e.g., price elasticity of rental demand, elasticity of supply, stock depreciation rate).

Acknowledgements This paper was based mainly upon the unpublished doctoral dissertation of the first author (Ozbakan 2016). We graciously appreciate the constructive and meticulous feedback received during the review process.

\section{References}

Allen, H., \& Taylor, M. P. (1990). Charts, noise and fundamentals in the London foreign exchange market. The Economic Journal, 100(400), 49-59.

Barberis, N., \& Thaler, R. (2003). A survey of behavioral finance. In G. M. Constantinides, M. Harris \& R. M. Stulz (Eds.), Handbook of the economics of finance (Vol. s.1, pp. 1053-1128). Amsterdam: Elsevier.

Bijman, I. T. (2012). Expectations in a nonlinear real estate model. Unpublished master's thesis. University of Amsterdam, Amsterdam.

Bolt, W. et al., (2013). Identifying booms and busts in house prices under heterogeneous expectations. Tinbergen Institute Discussion Papers, pp. 1-24.

Brock, W. A., \& Hommes, C. H. (1997). A rational route to randomness. Econometrica, 65(5), 1059-1095.

Brock, W. A., \& Hommes, C. H. (1998). Heterogeneous beliefs and routes to chaos in a simple asset pricing. Journal of Economic Dynamics and Control, 22(8-9), 1235-1274.

Burnside, C., Eichenbaum, M., \& Rebelo, S., (2011). Understanding booms and busts in housing markets. NBER Working Papers, Issue 16734, pp. 1-56.

Campisi, G., Naimzada, A. K., \& Tramontana, F. (2018). Local and global analysis of a speculative housing market with production lag. Chaos, 28(5), 055901.

Dieci, R., \& Westerhoff, F. (2012). A simple model of a speculative housing market. Journal of Evolutionary Economics, 22, 303-329.

DiPasquale, D., \& Wheaton, W. C. (1992). The markets for real estate assets and space: A conceptual framework. Journal of the American Real Estate and Urban Economics Association, 20(1), 181-197.

Eichholtz, P., Huisman, R., \& Zwinkels, R. C. J. (2015). Fundamentals or trends? A long-term perspective on house prices. Applied Economics, 47(10), 1050-1059.

Frankel, J. A., \& Froot, K. A. (1987). Expectations, using survey data to test standard propositions regarding exchange rate. The American Economic Review, 77(1), 133-153.

Frankel, J. A., \& Froot, K. A. (1990). Chartists, Fundamentalists and the Demand for Dollars. National Bureau of Economic Research, 1655, 73-126.

Harrison, J. M., \& Kreps, D. M. (1978). Speculative investor behavior in a stock market with heterogeneous expectations. The Quarterly Journal of Economics, 92(2), 323-336.

Himmelberg, C., Mayer, C., \& Sinai, T., (2005). Assessing high house prices: Bubbles, fundamentals and misperceptions. NBER Working Paper Series, Issue 11643, pp. 1-42.

Hommes, C. H. (2006). Heterogeneous agent models in economics and finance. In: L. Tesfatsion \& K. L. Judd (Eds.), Handbook of Computational Economics (Vol. s.1., pp. 1110-1146) Elsevier.

Kahneman, D., \& Tversky, A. (1979). Prospect theory: An analysis of decision under risk. Econometrica, 47(2), 263-291.

Kahneman, D., \& Tversky, A. (1984). Choices, values, and frames. American Psychologist, 39(4), 341-350. 
Kirman, A. (1993). Ants, rationality, and recruitment. The Quarterly Journal of Economics, 108(1), 137-156.

LeBaron, B. (2001). A builder's guide to agent-based financial markets. Quantitative Finance, 1(2), 254-261.

Ozbakan, A. T. (2016). Exploring house price dynamics: An agent-based simulation with behavioral heterogeneity. Unpublished doctoral dissertation. Izmir: Izmir Institute of Technology.

Poterba, J. M. (1984). Tax subsidies to owner-occupied housing: An asset-market approach. The Quarterly Journal of Economics, 99(4), 729-752.

Poterba, J. M. (1991). House price dynamics: The role of tax policy and demography. Brookings Papers on Economic Activity, 2, 143-203.

Simon, H. A. (1955). A behavioral model of rational choice. The Quarterly Journal of Economics, 69(1), 99-118.

Tversky, A., \& Kahneman, D. (1974). Judgment under uncertainty: Heuristics and biases. Science, 185(4157), 1124-1131.

Wheaton, W. C. (1999). Real estate “cycles": Some fundamentals. Real Estate Economics, 27(2), 209-230. 